\title{
CARACTERÍSTICAS BIOMÉTRICAS Y BIOLÓGICAS DE LA ESPECIE Cancer setosus EN EL ÁREA DE ILO
}

\author{
Olger Acosta Angulo', Luis Rivera \\ Chipana', José Angeles Millones'.
}

\section{INTRODUCCIÓN}

Dentro de la pesqueria marisquera del sur del país, la especie Cancer setosus representa un significativo porcentaje del desembarque total de invertebrados marinos del Puerto de llo, el mismo que en los últimos años se ha visto incrementado debido a su alto valor comercial.

El presente informe científico esta referido al estudio de los parámetros biométrico-biológicos del recurso Cancer setosus (Jaiba peluda) en el área de Ilo, durante los meses de octubre de 1994 a marzo de 1995.

La escasa literatura relacionada con esta especie nos motiva a dar un mayor énfasis a los aspectos relacionados al proceso reproductivo con la finalidad de desarrollar una escala macroscópica para la determinación de los estadios sexuales en los especímenes hembras, asi como la definición de las relaciones de longitud total del caparazón y peso húmedo.

\section{ANTECEDENTES}

\subsection{ASPECTOS BIOLÓGICOS}

\section{a) Morfología Externa}

La especie Cancer setosus es un decápodo provisto de una caparazón de forma semiovoide, cubierto de una cutícula resistente cuya superficie externa es áspera y provista de pelos quitinosos, presentando hacia el centro unas hendiduras bastante notables.

El caparazón es más ancho que largo y de aspecto peludo, de ahí la denominación de "jaiba peluda". Hacia la parte anterior se encuentran los ojos que son pedunculados y el borde anterior del caparazón es dentado. El primero y segundo par de antenas son pequeñas. Los tres primeros pares de apéndices torácicos están transformados en maxilipedos, porque cumplen la función de órganos bucales, siendo el tercer par de maxilipedos de regular tamaño y peludo. Los - cinco pares de apéndices restantes son torácicos, llamados también pereiópodos, transformados en patas. El primer par transformado en gnatopodios o quelas poco consistentes, ambas de igual tamaño.

El segundo, tercero, cuarto y quinto par de apéndices son patas ambulacrales que terminan en uñas punteagudas o garras, estando todas ellas cubiertas de pelos quitinosos.

En la parte ventral del individuo se encuentra el abdomen que es considerablemente reducido. En la hembra los pleópodos abdominales contribuyen a la respiración y cumplen la función de incubar los huevos, en cambio en los individuos machos solo están presentes los pleópodos copulatorios.

\section{b) Morfología Interna}

El sistema digestivo es completo, presenta boca, tubo digestivo y ano. El tubo digestivo empieza en el intestino anterior que se subdivide en esófago y estómago masticador, éste último provisto de placas quitinosas que sirven para triturar los alimentos. Sigue el intestino medio conformado por el estómago glandular y un intestino posterior.

Anexas al tubo digestivo se hallan las glándulas salivales y el hepatopáncreas, éste último es una voluminosa masa glandular formada por divertículos tubulosos del intestino medio con funciones secretoras y absorbentes. Poseen numerosos músculos estriados que le permiten moverse rápidamente. 
El sistema circulatorio es lagunar, porque las arterias y venas no se unen mediante los capilares sanguineos, si no que entre ellos existen unos espacios o lagunas que les sirven para comunicarse. El corazón es alargado, con ostiolos, que se encuentran localizados en la parte dorsal del tórax.

La sangre es incolora y contiene como pigmento respiratorio a la hemocianina.

\section{c) Nomenclatura}

Nombre cientifico: Cancer

setosus

(Chirichigno, 1970)

Nombres comunes: jaiba peluda, cangrejo.

Sinonimia

Chirichigno, N. (1970) cita
a Cancer setosus como
sinónimo de Cancer
polyodon.

d) Clasificación sistemática

$\begin{array}{ll}\text { Phylum } & \text { Arthropoda } \\ \text { Subphylum } & : \text { Mandibulata } \\ \text { Clase } & \text { : Crustacea } \\ \text { Subclase } & \text { : Malacostraca } \\ \text { Serie } & \text { : Eumalacostraca } \\ \text { Superorden } & \text { : Eucarida } \\ \text { Orden } & \text { : Decapoda } \\ \text { Suborden } & \text { : Reptantia } \\ \text { Supersección: Natantia } \\ \text { Sección } & : \text { Brachyura } \\ \text { Subsección } & : \text { Brachygnata } \\ \text { Superfamilia } & \text { Corystoidea } \\ \text { Familia } & : \text { Cancridae } \\ \text { Género } & : \text { Cancer } \\ \text { Especie } & \text { : Cancer setosus }\end{array}$

\subsection{ASPECTOS ECOLÓGICOS}

Cancer setosus vive en costas semiprotegidas de fondos pedregosos 0 arenosos en la cercanía de macizos rocosos. Se le ha observado en el medio natural, escondida y semienterrada en excavaciones que realizan en la arena al límite de paredes de roca. Acostumbra a cubrirse de arena y conchuela. Parece preferir aguas claras y bien oxigenadas. Se distribuyen por debajo de la zona mareal hasta 45 metros de profundidad.

Haig (1967) informa que la distribución en el Perú de esta especie abarca desde Pacasmayo, Salaverry, Bahía de Ancón, Callao, Isla San Lorenzo, Islas de Chincha y Bahía de la Independencia.
Castellanos (1980) afirma que en la región de Tacna y Moquegua esta especie se halla distribuida desde el Balneario de Llostay (Tacna) hasta Yerbabuena (limite de Moquegua con Arequipa), comprendiendo las zonas de mayor extracción Vila Vila (La Yesera), Tres Hermanas y Pocoma.

Según Enriquez y Bahamonde (1976) esta especie se distribuye desde Guayaquil, $3^{\circ} \mathrm{S}$ (Ecuador) hasta la Peninsula de Taitao, $47^{\circ} \mathrm{S}$ (Chile).

En la Isla San Lorenzo (Perú) ha sido encontrada en profundidades de 0,3 á 2,5 metros.

\subsection{ASPECTOS REPRODUCTIVOS}

\section{a) Sexualidad}

La especie Cancer setosus es un decápodo dioico, de sexos separados. Presenta dimorfismo sexual, por la forma del pleópodo se puede determinar si la especie es macho o hembra, será hembra cuando el pleópodo tenga la forma semi circular y macho cuando el pleópodo tiene forma punteaguda.

\section{b) Sistema reproductor}

El sistema reproductor masculino está formado por los testículos, apareados pero conectados, que se encuentran en la parte anterior del abdomen. Los espermatozoos de esta especie no poseen cola. El extremo terminal del conducto espermático es un tubo muscular eyaculador, que se abre sobre la membrana articular situada entre la coxa y el esternón. Tiene dos penes tubulares así como todos los braquiuros. Los dos primeros pleópodos en el macho están modificados para ayudar a la transferencia de espermatozoos.

El sistema reproductor femenino de esta especie está constituido por los ovarios y el oviducto, pareciéndose en estructura y localización los ovarios a los testículos.

El extremo terminal de cada oviducto se halla modificado y convertido en vagina y receptáculo seminal glandular para la recepción del pene.

\section{c) Ciclo reproductivo}

Las hembras que viven en aguas salobres retornan al agua de baja salinidad para permitir la incubación de los huevos. Se ha observado hembras con huevos en julio y 
octubre, la fecundidad es alta habiéndose calculado aproximadamente 2'000.000 de huevos en una hembra.

La etapa de incubación es una larva zoea que vive en el plancton cierto tiempo. Mudas sucesivas transforman la larva zoea en una larva megalopa, que posee muchos rasgos de cangrejo, pero todavia con el abdomen desplegado. Un desarrollo ulterior conduce a la forma adulta del cuerpo.

\subsection{ASPECTOS PESQUEROS}

Este recurso que forma parte de la economia regional es extraido por embarcaciones artesanales empleando la modalidad de buceo con compresora.

En el Puerto de llo entre los años 1990 - 1993, de la captura total de invertebrados marinos, Cancer setosus registró los siguientes desembarques:

\begin{tabular}{ll|} 
- En 1990 & $19,20 \operatorname{TM}(12,40 \%)$ \\
- En 1991 & $10,92 \operatorname{TM}(2,92 \%)$ \\
- En 1992 & $22,45 \operatorname{TM}(5,40 \%)$ \\
- En 1993 & $20,53 \operatorname{TM}(4,08 \%)$ \\
\hline
\end{tabular}

Fuente: Ministerio de Pesquería

\section{MATERIALES Y MÉTODOS}

\subsection{ZONA DE ESTUDIO}

El presente trabajo tuvo como ámbito el litoral comprendido entre la zona denominada La Isla $\left(17^{\circ} 15^{\prime}\right.$ 's) y la zona denominada Picata ( $\left.17^{\circ} 52^{\prime} \mathrm{S}\right)$. Con fines del estudio esta área fue dividida en cinco zonas: La Isla, Pocoma, Fundición, Punta de Coles y Picata, las mismas que conforman la preferencia de los pescadores artesanales del Puerto de llo (véase anexo $N^{0} 1$ ).

\subsection{OBTENCIÓN DE LA MUESTRA}

De octubre de 1994 a marzo de 1995 se colectó un total de 217 ejemplares de Cancer setosus, tomados de las diferentes zonas de trabajo a bordo de embarcaciones artesanales dedicadas a la extracción de invertebrados marinos, con capacidades de bodega que oscilan de 2 á 4 TM.

Las muestras obtenidas de cada zona representan el $10 \%$ de la captura total de la faena de pesca, tomando también información del esfuerzo pesquero realizado.

\subsection{MEDICIONES BIOMÉTRICAS}

En el Laboratorio Costero del IMARPE ILO los ejemplares obtenidos en el muestreo al azar fueron medidos (longitud y ancho del caparazón) y pesados (peso fresco total del cuerpo).

\subsection{ANÁLISIS BIOLÓGICO}

\section{- Determinación del sexo}

Los ejemplares de la muestra fueron separados por sexos, teniendo como criterio de clasificación las siguientes caracteristicas macroscópicas.

a) Machos:presentan el pleópodo en forma punteaguda.

b) Hembras: presentan el pleópodo en forma semicircular y además la presencia de huevos fecundados.

\section{- Determinación del estadio sexual}

La determinación del estadio sexual se hizo solamente en hembras, para lo cual sugerimos la siguiente escala:

Estadio I : corresponde a las hembras virginales.

Estadio II : corresponde a hembras adultas en estado madurante que inician o reinician un nuevo ciclo de desarrollo gonadal.

Estadio II-1: óvulos de coloración naranja rojizo de pequeño tamaño no fecundado que ocupan internamente la cuarta parte de la cavidad torácica.

Estadio II-2: óvulos de coloración naranja rojizo de tamaño pequeño no fecundado que internamente ocupan la mitad de la cavidad torácica.

Estadio II-3 : óvulos de coloración naranja nitido que se observan de mayor diámetro que los anteriores ocupando toda la cavidad torácica (abundante masa ovigera)

Estadio III : corresponde a hembras que presentan huevos fecundados inmaduros localizados externamente y fijados entre las 
cerdas del pleópodo, debajo del abdomen plegado.

Estadio III-1: huevos bastante visibles con coloración anaranjado rojizo intenso.

Estadio III-2: huevos visibles con coloración naranja parduzco.

Estadio IV : corresponde a hembras que presentan huevos madurantes próximos a eclosionar.

Estadio IV-1:huevos fecundados con coloración amarillo ocre con tendencia a marrón claro.

Estadio IV-2: huevos fecundados con coloración pardo grisáceo tendiente a gris oscuro, próximos a eclosionar.

Estadio V : corresponde a hembras completamente desovadas.

- CONTENIDO ESTOMACAL

Se tomaron algunos individuos de la muestra para el reconocimiento de su contenido estomacal, el mismo que se realizó mediante observación directa con ayuda de una lupa 10 $x$.

\section{RESULTADOS}

\subsection{EVALUACIÓN BIOMÉTRICA}

La evaluación biométrica de la muestra estudiada por zonas, establece los siguientes resultados:

\section{Zona I: LA ISLA}

Límites

:Desde La Isla $\left(17^{\circ} 15^{\prime} \mathrm{S}\right)$ hasta Punta

El Carmen $\left(17^{\circ} 22^{\prime} \mathrm{S}\right)$

Aparejo

: Compresora

Ejemplares colectados : 46

$\begin{array}{ll}\text { Rangos de tallas } & : 78 \mathrm{~mm} \text { á } 103 \mathrm{~mm} \\ \text { Longitud promedio } & : 92,1 \mathrm{~mm}\end{array}$

Zona II: POCOMA

Limites

: Desde Punta del Carmen $\left(17^{\circ} 22^{\prime} \mathrm{S}\right)$ hasta Punta

Sopladera (1730'S)

Aparejo : Compresora

Ejemplares colectados : 13

Rangos de tallas

: $57 \mathrm{~mm}$ á $79 \mathrm{~mm}$

\section{Longitud promedio $\quad: 69,5 \mathrm{~mm}$}

Zona III: FUNDICION

Limites

:Desde Punta

Sopladera (1730'S)

hasta el Puerto de llo

(173'ㅇ)

Aparejo : Compresora

Ejemplares colectados : 61

Rangos de tallas $\quad: 65 \mathrm{~mm}$ á $97 \mathrm{~mm}$

Longitud promedio $: 82,92 \mathrm{~mm}$

\section{Zona IV : PUNTA COLES}

Límites

: Desde Puerto de llo

$\left(17^{\circ} 39 ' S\right)$ hasta Pozo

Aparejo de Lisas $\left(17^{\circ} 45^{\prime} \mathrm{S}\right)$

Ejemplares colectados : 60

Rangos de tallas

: $67 \mathrm{~mm}$ á $95 \mathrm{~mm}$

Longitud promedio

: $82,03 \mathrm{~mm}$

\section{Zona V: PICATA}

Limites

: Desde Pozo de Lisas $\left(17^{\circ} 45^{\prime} \mathrm{S}\right)$ hasta Santa Rosa (17०52'S)

Aparejo : Compresora

Ejemplares colectados : 37

Rangos de tallas $\quad: 60 \mathrm{~mm}$ á $95 \mathrm{~mm}$

Longitud promedio $: 76,57 \mathrm{~mm}$

En general para toda el Area de Ilo:

Límites

:Desde La Isla $\left(17^{\circ} 15^{\prime} S\right)$ hasta Santa Rosa(1752'S)

Aparejo : Compresora

Ejemplares colectados : 217

$\begin{array}{ll}\text { Rangos de tallas } & : 57 \mathrm{~mm} \text { á } 103 \mathrm{~mm} \\ \text { Longitud total } \bar{X} & : 82,73 \mathrm{~mm}\end{array}$

Ancho del caparazón $\bar{X}: 117,82 \mathrm{~mm}$

Peso húmedo $\bar{X}$

: 270,74 gramos

La composición por tallas del universo de ejemplares muestreados se grafican en la figura $N^{\circ} 1$ donde se presentan intervalos de clases de 3 milimetros por clase, con una moda representada por el intervalo de clase integrado por las longitudes 78-79-80 milímetros.

Las relaciones talla-peso por zonas se muestran en las fig. $N^{\circ} 2,3,4,5$ y 6 .

Las relaciones talla-peso para toda el área de llo se grafica en la fig. $N^{\circ} 7$.

La estimación de regresión y correlación talla-peso total por zonas y para toda el área de 
llo se presentan en la tabla $N^{0} 1$, cuya fórmula general es:

donde:

$$
w=q L^{b}
$$

$\mathbf{w}=$ peso húmedo.

$\mathrm{L}=$ Longitud del caparazón.

$q=$ factor de condición, constante de la relación longitud - peso.

$\mathrm{b}=$ pendiente.

Para toda el área la fórmula general calculada es:

$$
w=0,00355 L^{2,542}
$$

Tabla $N^{\circ}$ 1. Valores de regresión $(a, b, r)$ de las relaciones tallapeso total para las zonas muestreadas.

\begin{tabular}{|l|c|c|c|}
\hline \multicolumn{1}{|c|}{ ZONA } & a & b & $r$ \\
\hline La Isla & 0,00893 & 2,312 & 0,873 \\
\hline Pocoma & 0,00941 & 2,345 & 0,677 \\
\hline Fundición & 0,00355 & 2,542 & 0,823 \\
\hline Punta de Coles & 0,00046 & 2,985 & 0,857 \\
\hline Picata & 0,00657 & 2,405 & 0,808 \\
\hline TOTAL & 0,00355 & 2,542 & 0,823 \\
\hline
\end{tabular}

Donde: $\quad a=$ intersepto

$\mathrm{b}=$ pendiente

$r=$ coeficiente de correlación

\subsection{ANÁLISIS BIOLÓGICO}

Se presentó una proporción sexual de 5:1 a favor de las hembras.

En la tabla $\mathrm{N}^{\circ} 2$ se muestra la distribución porcentual de las hembras por estadio de madurez sexual.

Tabla $N^{\circ} 2$. Distribución y composición porcentual de las hembras de Cancer setosus por estadios de

\begin{tabular}{|c|c|c|c|c|c|c|c|c|c|c|}
\hline \multirow{3}{*}{ FRECUENCA } & \multicolumn{9}{|c|}{ ESTADIO SEXUAL } & \multirow{3}{*}{ TOTA } \\
\hline & 1 & \multicolumn{3}{|c|}{$\|$} & \multicolumn{2}{|c|}{ III } & \multicolumn{2}{|c|}{ IV } & $\mathrm{V}$ & \\
\hline & 1 & 1 & 2 & 3 & -1 & 2 & 1 & 2 & 1 & \\
\hline $\mathrm{n}$ & 0 & 31 & 33 & 18 & 25 & 22 & 10 & 8 & 34 & 181 \\
\hline \multirow[t]{2}{*}{. } & 0 & 17.13 & 18.23 & 9.95 & 13.81 & 12.16 & 5.52 & 4.42 & 18.78 & 100 \\
\hline & 0 & \multicolumn{3}{|c|}{45.31} & \multicolumn{2}{|c|}{25.97} & \multicolumn{2}{|c|}{9.94} & 18.78 & \\
\hline
\end{tabular}
madurez sexual.

\subsection{CONTENIDO ESTOMACAL}

En el análisis de contenido estomacal, de 40 ejemplares tomados al azar de toda la muestra, se observó macroscópicamente que Cancer setosus tiene hábitos carnivoros o detritívoros.

\section{CONCLUSIONES}

a) De acuerdo a la composición biométrica, la muestra tratada presenta una distribución por tallas bimodal con picos en $79 \mathrm{~mm}$ y $85 \mathrm{~mm}$, encontramos también que las tallas mínima de $57 \mathrm{~mm}$ y máxima de 103 $\mathrm{mm}$ coinciden con los reportes de esta especie en el litoral chileno (Lorenzen et al, 1979).

b) La zona de La Isla es la que registra individuos de mayor talla y por tanto la más alta longitud media, $92,1 \mathrm{~mm}$ y la zona de Pocoma registra las menores longitudes con una media de $69,5 \mathrm{~mm}$.

c) Las relaciones talla-peso total, por zonas, son similares para La Isla, Pocoma, Fundición y Picata; en la zona de Punta de Coles observamos una disminución del peso en relación a la talla, motivado quizás porque esta zona tiene un alto índice de intervención humana, por ser preferida por extractores de mariscos, lo que nos determina que el rendimiento de la parte nutritiva es menor.

d) Existe una relación lineal directa entre la longitud del caparazón y el peso húmedo, demostrado por el coeficiente de correlación para toda el área $(r=$ 0,823).

e) El mayor porcentaje de hembras muestreadas se encuentran en el estadío sexual II, o sea que están en pleno proceso de ovulación; y la menor proporción de éstas se encuentran localizadas en el estadio sexual IV; ninguna hembra es virginal. La proporción sexual fue de 5:1 favorable a las hembras.

f) Los resultados del análisis de contenido estomacal nos certifica los hábitos detritívoros de la especie. 


\section{REFERENCIAS BIBLIOGRÁFICAS}

ALEGRÍA, V. \& AVILÉS, A. OBSERVACIONES PRELIMINARES SOBRE LA MADUREZ EL LANGOSTINO.

COLL, M.J. ACUICULTURA MARINA. ED. MUNDI PRENSA.

CHIRICHIGNO, N. LISTA DE CRUSTÁCEOS DEL PERUं (DECAPODAY STOMATÓPODA) CON DATOS DE DISTRIBUCIÓN GEOGRÁFICA. IMARPE - CALLAO 1970.

LAEVASTU, T. MANUAL DE MÉtodos dE BIOLOGIA PESQUERA. EDITORIAL ACRIBIA - ESPAÑA.

LÓPEZ, C.O. \& GIESCHEN, R.E. ZOOLOGÍA AGRÍCOLA. EDITORIAL ATENEO - BUENOS AIRES 1946.

LORENZEN, S. \& OTROS. MARISCOS Y PECES DE IMPORTANCIA COMERCIAL EN EL SUR DE CHILE. UNIVERSIDAD AUSTRAL DE CHILE VALDIVIA 1979.

MÉNDEZ, M. CRUSTÁCEOS COMERCIALES Y OTRAS ESPECIES COMUNES EN EL LITORAL PERUANO BOLETIN DE LIMA Nº 201982.

NOVIKOV, M. FUNDAMENTOS DE LA MORFOLOGIA COMPARADA DE LOS INVERTEBRADOS. EDITORIAL EUDEBA - BUENOS AIRES 1963

PRATT, H.S.MANUAL DE INVERTEBRADOS COMUNES. EDITORIAL MC GRAW HILL BOOK CO. NY.

RABÍ, M. \&QUIROZ, M. PROSPECCIÓN PESQUERA DEL
RECURSO CHANQUE, CONCHOLEPAS CONCHOLEPAS (BRUGUIERE, 1789) EN LA REGIÓN JOSÉ CARLOS MARIÁTEGUI, JULIO DE 1994. INFORME IMARPE

SALZWEDEL, H. RECURSOS Y DINÁMICA DEL ECOSISTEMA DE AFLORAMIENTO PERUANO IMARPE - BOLETÍN EXTRAORDINARIO CALLAO PERUं 1988

SÁNCHEZ, J. \&ZIMIC, E.HISTORIA MARITIMA DEL PERÚ TOMO I - VOL. 2, LIMA - PERÚ 1973

SMITH \& WELDON .CRUSTÁCEOS.ED. MACMILLAN Y CO. LONDRES

TAIT, R.V. ELEMENTOS DE ECOLOGIAA MARINA ED. ACRIBIA ESPAÑA.

TALLEDO, C. \&ISHIYAMA, V. CICLO REPRODUCTIVO DE LAS HEMBRAS DE CANCER SETOSUS (CRUSTACEA, DECAPODA) DEL LITORAL DE LIMA, PERÚ. IMARPE - CALLAO 1979.

VIACAVA, M. \& OTROS. ESTUDIO DEL CAMARÓN EN EL PERÚ. IMARPE - BOLETÍN N 5 - VOL. 3 CALLAO - PERÚ 1978.

WOOD, P.C. MANUAL DE HIGIENE DE LOS MARISCOS. ED. ACRIBIA - ESPAÑA
Figura N6 - Relación Talla - Peso de Cancer setosus en la zona de Picata.

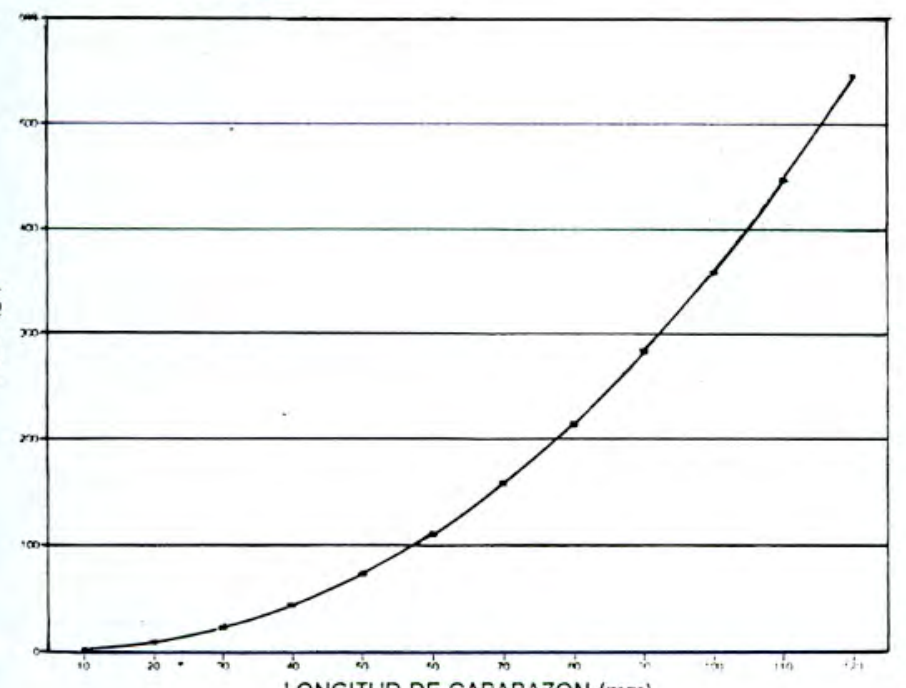

LONGITUD DE CAPARAZON $(\mathrm{mm})$
Flgura $\mathrm{N}^{\circ} 7$ - Relación Talla - Peso de Cancer setosus en el área de llo.

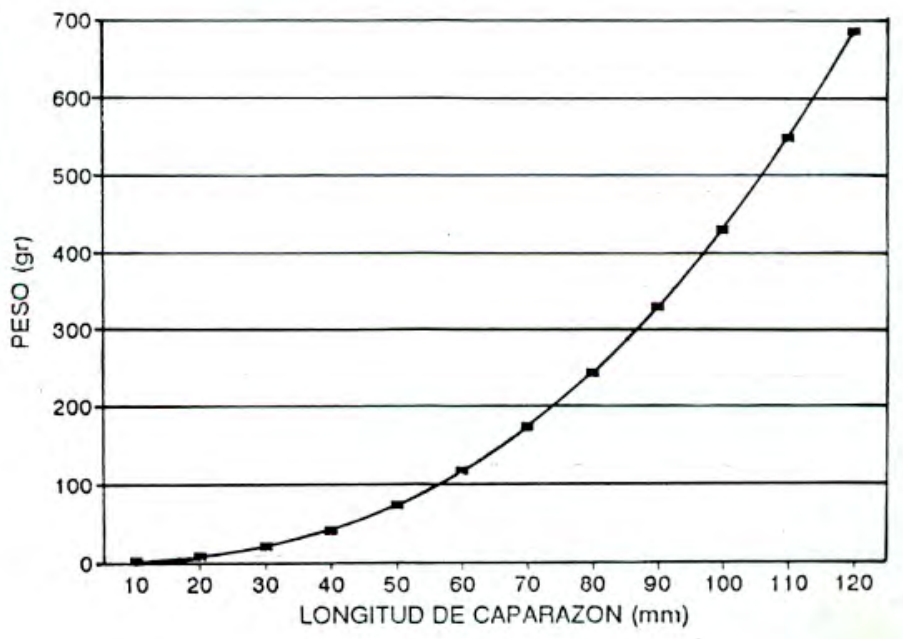




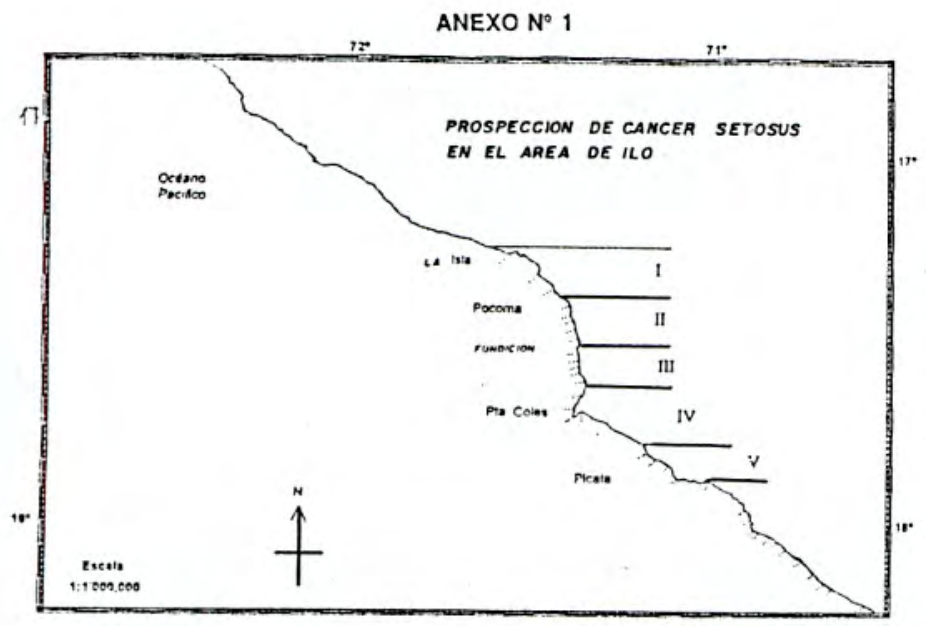

Figura $\mathrm{N}^{\circ} 2$ - Relación Talla - Peso de Cancer setosus en la zona de La Isla.

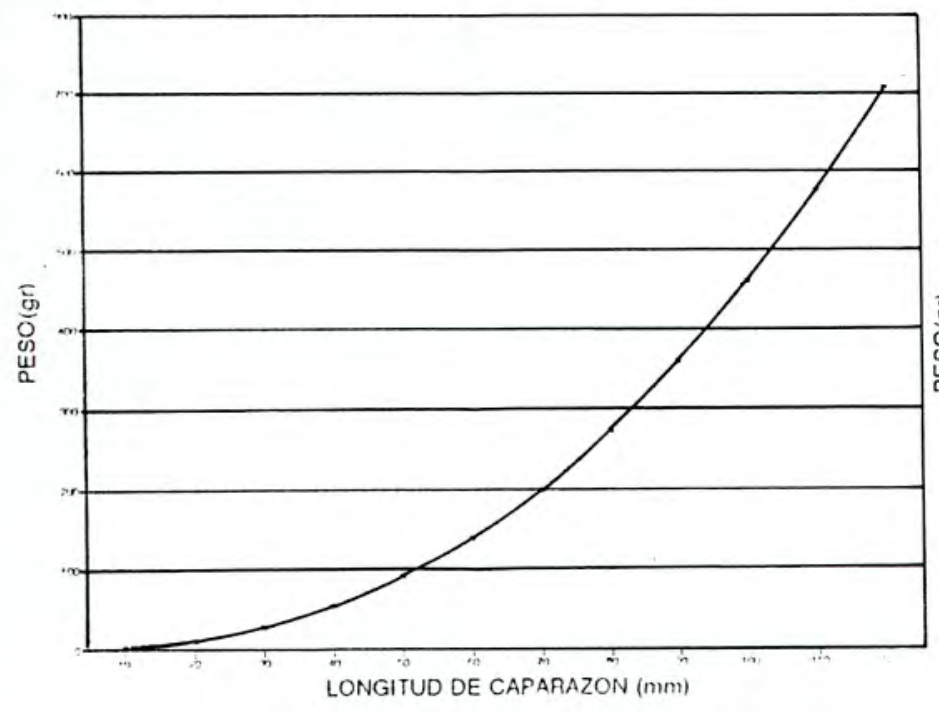

Flgura $N^{\circ} 4$ - Relación Talla - Peso de Cancer setosus en la zona de Fundición

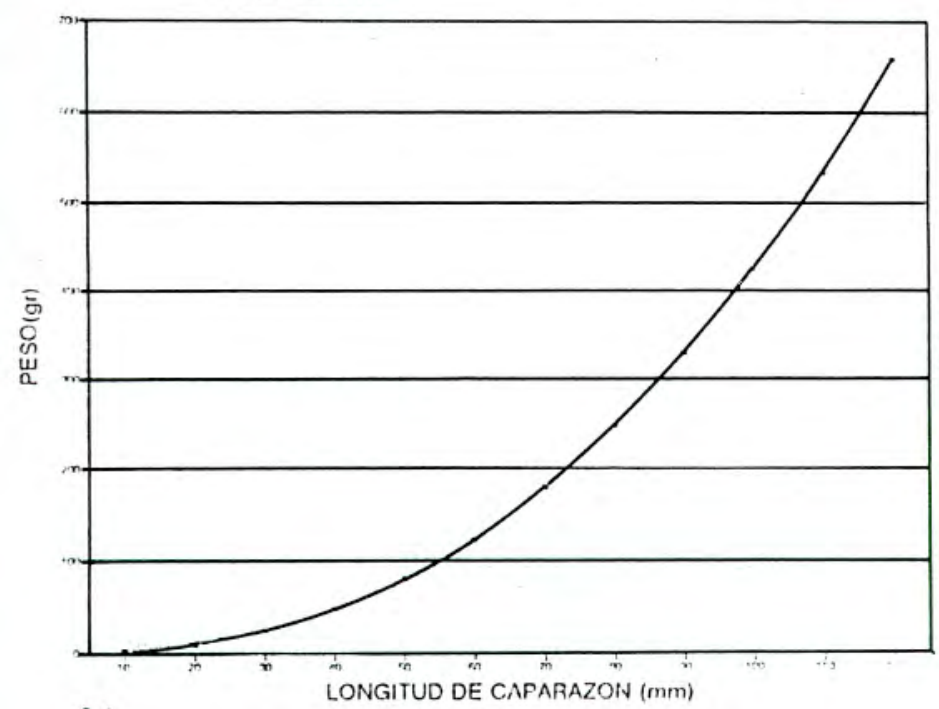

Flgura $N^{\circ} 1$ - Composición Biométrica de Cancer setosus en el Area de llo.

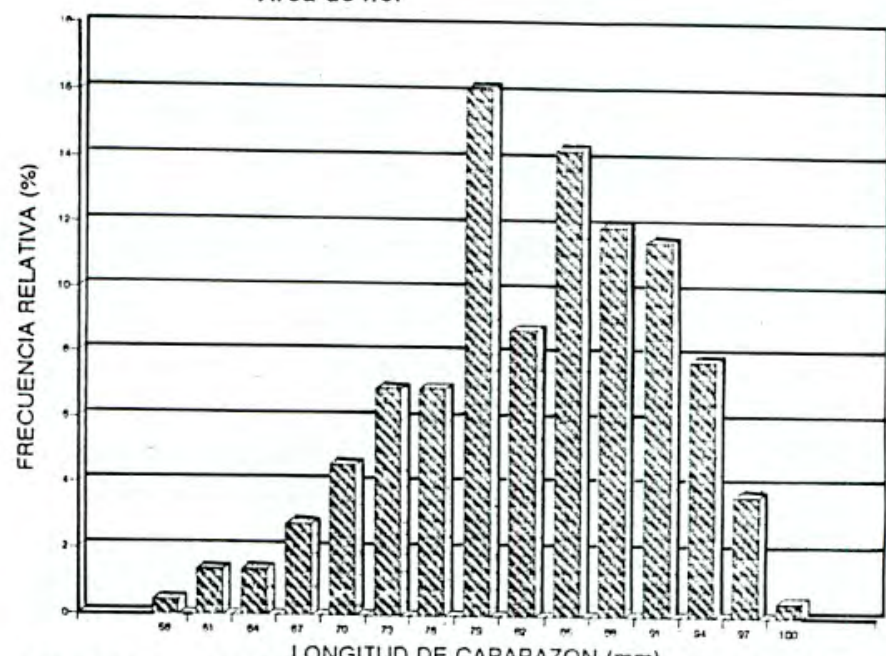

Figura $N^{\circ} 3$ - Relación Talla - Peso de Cancer setosus en la zona de Pocoma.

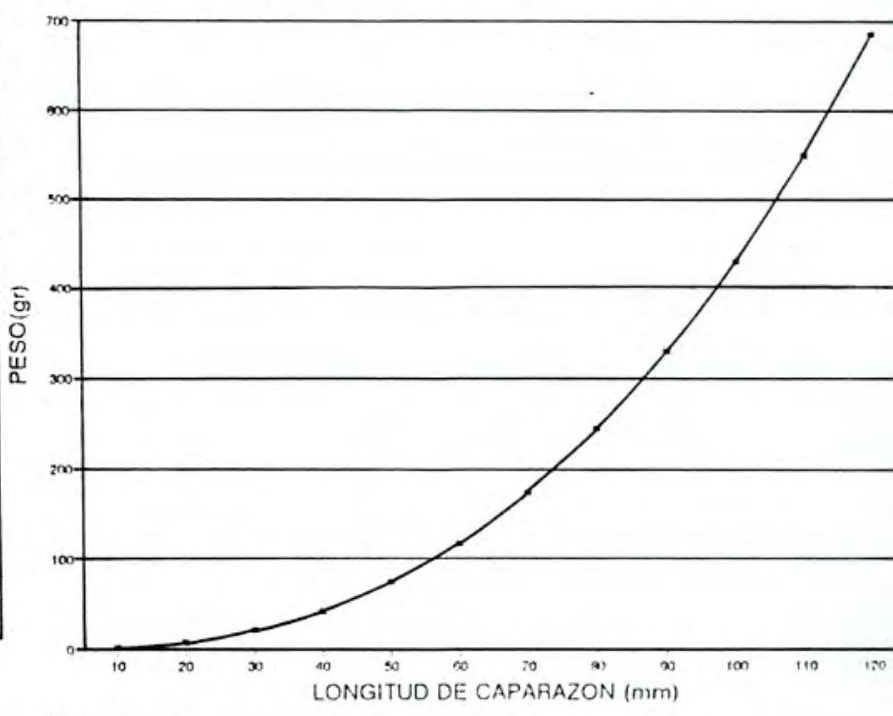

Flgura $N^{\circ} 5$ - Relación Talla - Peso de Cancer setosus en la zona de Punta de Coles

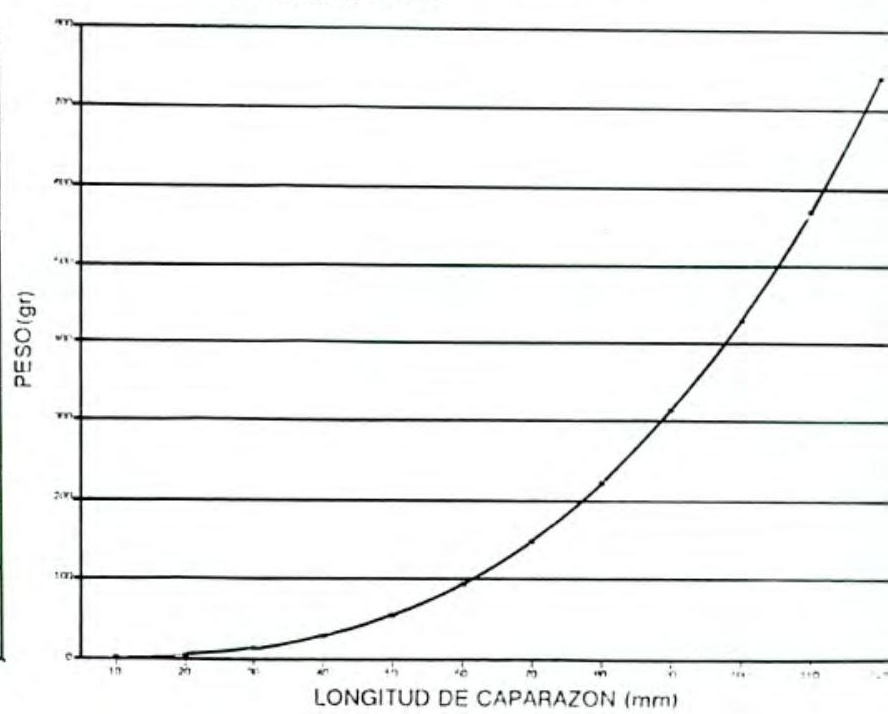

